\title{
IoT based Car Parking Management System using IR Sensor
}

\author{
Muhamad Muzhafar Abd Kadir ${ }^{1}$, Mohd Nizam Osman ${ }^{2 *}$, Nor Arzami Othman ${ }^{3}$, \\ Khairul Anwar Sedek ${ }^{4}$ \\ ${ }^{1,2,3,4}$ Faculty of Computer and Mathematical Sciences, Universiti Teknologi Mara, Perlis Branch, 02600 \\ Arau, Perlis, Malaysia \\ Corresponding author:*mohdnizam@uitm.edu.my \\ Received Date: 1 September 2020 \\ Accepted Date: 9 October 2020
}

\begin{abstract}
This paper proposes an IoT based Car Parking Management System that is developed to display the vacant or available parking slot. It integrates a nodeMCU as microcontroller with IR sensor and LCD screen. The IR sensor is used to detect the absence or presence of a car when it enters the parking slot, and the LCD screen is then used to display the vacant parking slot to the driver. The parking slots are continuously monitored, and the data is continuously updated in the LCD screen. The proposed parking system is developed using the Internet of Things (IoT) technology with the minimum cost, effective and efficient. The main purpose of the proposed parking system is to help or assist drivers in finding a vacant parking slot. Furthermore, the proposed parking system can also record the availability status of parking slot and the exact time a car enters or exits a parking slot in the database for the use of the administrative management. Thus, it also helps the drivers in reducing their time spent in finding vacant parking slots. As such, the drivers save their energy and will help reduce the traffic congestion in the parking area. The prototype for proposed parking system was developed to visualize and stimulate the real parking system environment, and a demonstration of the prototype has proven the capability of the system to reserve the exact location of the parking slot by displaying on the LCD screen. Then, a user acceptance test was conducted with 30 respondents to determine the effectiveness of the prototype for the proposed parking system. The result obtained from the testing was positively accepted by most of the participants. Therefore, the proposed parking system has been proven to be beneficial to the drivers and can also motivate other developers to contribute to more future projects to help the drivers in finding a vacant parking slot easily.
\end{abstract}

Keywords: Car Parking Management System, IR sensor, LCD screen, nodeMCU microcontroller, IoT

\section{INTRODUCTION}

In big cities where the numbers of cars have increased, finding a parking space has been a very challenging task for most drivers, which have resulted in a number of practical conflicts. As mentioned by Srikanth et al., (2009), parking problems are becoming pervasive and ever growing in at an alarming pace in every city. There have been a lot of research and development being conducted all over the world to implement a better parking management system. One of the methods suggested to overcome this issue is using the Internet of Things (IoT) technology. "IoT plays a vital role in connecting the surrounding environmental things to the network and made easy to access those uninternet things from any remote location" (Rao, 2017). With the existence of this technology, it is possible to turn anything. According to Ali. et at., (2015), Internet of Things has come up as a new technology that is used to indicate a modern wireless telecommunication network as well as an intelligent node interconnected in a dynamic global infrastructure network. Furthermore, IoT is also being understood as the implementation of a connectivity concept of anything from anywhere at any given time. 
There are many types of the parking systems that have been developed using the IoT technology. For example, the Wireless Sensor Networks (WSNs). According to Larisis et al., (2013) "WSNs technology has a wide spectrum of applications, which are deeply embedded into the everyday world up to vehicle detection." Infrared (IR) sensor is also a part of the WSNs technology and it is commonly used in developing a smart parking system. IR sensor is used to detect obstacles by emitting infrared radiation. It is also known as the general-purpose proximity sensor. According to Choudhri et al., (2015), IR sensor can sense or measure the heat and the motion of an object. Hence, IR sensor is the suitable sensor to detect the movement or the motion of a vehicle when it is occupying the parking space.

The selection of the IR sensor to be implemented in the car parking system is to highlight the potential solution that can help to improve the process of finding a vacant parking space which becomes troublesome for most of the car users. Besides, most of the car parking available today, especially in the shopping malls or tourist places or any other commercial areas have a major drawback of the parking system which the system helps the user to find the available spaces for parking but not the exact location of the parking slot. Therefore, the existing of IoT technology is one of the popular elements to use when it comes to the parking system. As we all know, the difficulty to find a vacant parking space is on the rise and if the IoT technology is adapted to the parking management system, it is expected to ease and help the citizen, especially for whom finding an available parking space is their daily routine in life. With the existence of this technology, it is possible to improve the quality of life. Developing an IoT based Car Parking Management System using an IR sensor will indicate to the drivers the available parking space in the exact parking slot fast, easy and efficiently. This is because there will be IR sensor to detect whether there is a vehicle or not in the parking slot and LCD screen located in front of the entrance parking zone to display the exact location of available parking slot to the driver. Hence, the driver can save their time, vehicle fuel and energy in finding a vacant parking space and also will bring positivity to their daily life because they do not have to face frustration when it comes to finding a vacant parking space.

In this paper, we have developed an IoT based Car Parking Management System using IR sensor. This system has been developed in order to make the process of finding a vacant parking space becomes easier, faster and cost effective. Furthermore, the advantage of the proposed system, it can show the exact location of the parking slot to the user. The rest of this paper is organized as follows. In section 2, the previous study is presented with the related works on IR sensor implemented in various fields and systems. Section 3 presents the methodology which covers the architecture and detail implementation of the proposed parking system. Section 4 discusses the result from the experiments conducted. We conclude the paper in section 5 .

\section{PREVIOUS STUDIES}

This section is an overview several of related works on implementation of IR sensor technologies in various systems and approaches conducted by the researchers.

\section{Using IR Sensor for a Smart Home and Smart Security}

A group of researchers proposed to develop and introduce smart home system using IR sensor technology, which will detect the presence of persons whenever they enter into a particular zone to control the room's lights. The IR sensor will send this information to the controller. In this system, the IR sensor and relay are connected with the network. After the controller received the information, it sends out the signal to particular relay, and the appliance will be turned on or off. The system has four IR sensors that being connected to a microcontroller (Chowdary et al., 2015). 
Mitra et al., (2019) developed a similar smart home system that uses IR sensor to detect human movement in a confined space. There are two IR sensors to detect whether people are entering or leaving a room. This system also uses an LED indicator to show the IR sensor detected the movement of people.

Kausalya et al., (2018) implemented a smart home security using IR sensor. The IR sensor was used to detect a movement of person and being placed at the entrance of a house. The Arduino Uno board is connected to this sensors and camera module. Then, the Arduino Uno board was connected to NodeMCU board. When the sensor detects any movement, the camera module turned on and captured the picture of the person in front of the entrance of a house. This capture image will then be stored in the folder of house owner's PC and it will send captured images to the user email. The results also can be seen in a smart phone.

\section{Using IR Sensor for Traffic Management}

Rani et al., (2017) developed the traffic management system by utilize an IR sensor to detect the obstruction when a vehicle passes through. The IR sensor will receive the signal when the car is crowded on the road and when there is a long obstruction. The roads that have more traffic will have more time to get pass the traffic light while the roads that have less traffic experience less time. These IR sensors are used to ensure incoming vehicles meet the signal on the side of the road. Then, the Raspberry Pi controller works as a central console to determine which sideways of the road signal is to get open or close based on data gathered from the sensors. The Raspberry Pi commands the traffic control to display the relevant signal based on traffic density.

Meanwhile, Deekshitha et al., (2017) proposed and developed the traffic management system based on IR sensor. The system is designed for traffic jam detection, and the idea is to count the direction of the car wisely. A display screen on each main road will warn the car owner about traffic jams. In each signal and main road, the system will use two IR sensors. The counter rises when the vehicle is detected with the first detector. The counter is added to the "vehicle count" and the previous counter decreases when the second sensor senses the vehicles. If the first sensor detects any vehicles and the second sensor senses no vehicle for a certain duration, it takes the conclusion that a traffic jam has been occurred. The IR sensor was connected to the 8051-family microcontroller.

\section{Using IR Sensor for Garbage Monitor}

A group of researchers was introduced a garbage monitoring system using IR sensor technology (Agarwal et al., 2017). This system is trying to avoid the dustbin to overflow. The system architecture is divided into various parts, which is LCD, LED, Buzzer, IR sensors, Arduino Uno, Power Supply and Wi-Fi module. The garbage will be put inside the dustbin, and its level will be detected by the IR sensor. The LED will light up at different levels, indicating the amount of trash bin filled up by garbage. The LCD will display the capacity of the trash bin filled up by garbage. When the trash bin is filled up to $80 \%$ of its capacity, the buzzer will start ringing. A message, indicating that the trash bin is almost filled up, will be sent to the desired device using the Wi-Fi module which is integrated within the NodeMCU.

There is a similar system that focuses on the garbage monitoring system which was developed by Bhor, Morajkar, Gurav and Pandya. Same as the previous system, this system focuses on detecting the level of the garbage. In this system, four IR sensors are used to show the various levels of the waste collected in the bucket. The output will be given to the microcontroller to send the message to the control room via GSM module (Morajkar et al., 2015). 


\section{METHODOLOGY}

This section elaborates approaches used in the development process for the proposed car parking system using IoT technology.

\section{Developing the System Architecture for loT Based Car Parking Management System using IR Sensor}

Figure 1 shows the system architecture for the IoT based Car Parking Management System using IR sensor. The system consists of IR sensor, NodeMCU, LCD display and a web server to store database.

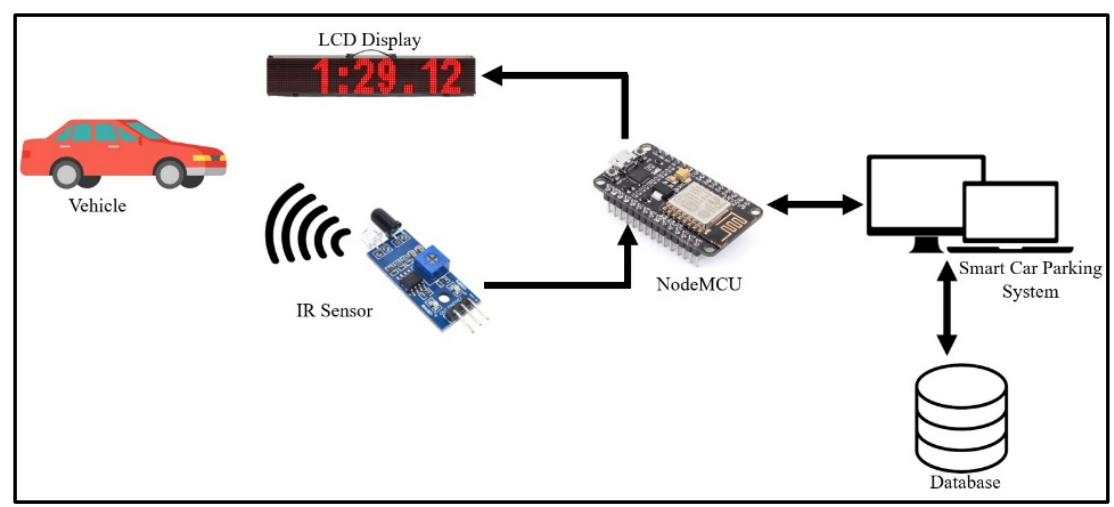

Figure 1: IoT based Car Parking Management System Architecture

The proposed parking system using IoT technology and the system involves the user who is driving his/her vehicle into the parking lot. First, when the user enters an available parking space, the IR sensor detected the presence of his/her vehicle. The IR sensor and LCD display are connected to NodeMCU as a microcontroller. After IR sensor has detected the presence of the vehicle, the LCD screen displays the available vacant parking space for the other user to park the car. Furthermore, the LCD screen displays the exact location of the parking slot to the user. The process also involved the database to store the availability of parking space data received from the IR sensor. All data in the database can be accessed through the interface provided by the car parking management system. Meanwhile, microcontroller is connected to the Internet by using an access point. This is important to ensure that the microcontroller can send data to the database when the IR sensor detecting the presence or absence of a car in a parking slot. The data that will be sent to the database will involve the availability status of a parking slot and time when a car enters and exits the parking slot. The data can be viewed by the administration of the parking zone.

\section{Implementation of IoT based Car Parking Management System using IR Sensor}

This sub topic discusses the activities to be setup by the requirement hardware and software used for the development of proposed car parking system using IR sensor. There are many types of hardware used to develop the proposed system such as IR sensor, NodeMCU, LCD display, jumper wire cables, breadboard and micro USB. Moreover, there are three types of software used for this proposed system, which are Arduino IDE, Notepad++ and XAMPP. Arduino IDE software is used to program or communicate between IR sensor and LCD display with the NodeMCU microcontroller. Meanwhile Notepad++ and XAMPP software is used for the development of the interface and database of the proposed car parking management system. 
The main objective is to design and develop a car parking system using the IR sensor technology to detect the vehicle. The process involved designing the car parking system with IR sensor. This IR sensor is used to detect vehicle when it enters a vacant parking space. Besides, this proposed system also used the LCD display screen to display the vacancy of a parking slot. All data collected will be stored in the database and can be accessed through the interface provided by the car parking management system. The aim of the proposed parking system is to ensure that the structured information application given is able to function and operate well. Therefore, the prototype of car parking system was designed and integrated with the car parking management system in a small scale to be tested to the users. Figure 2 shows the prototype of the proposed car parking management system using IR sensor.

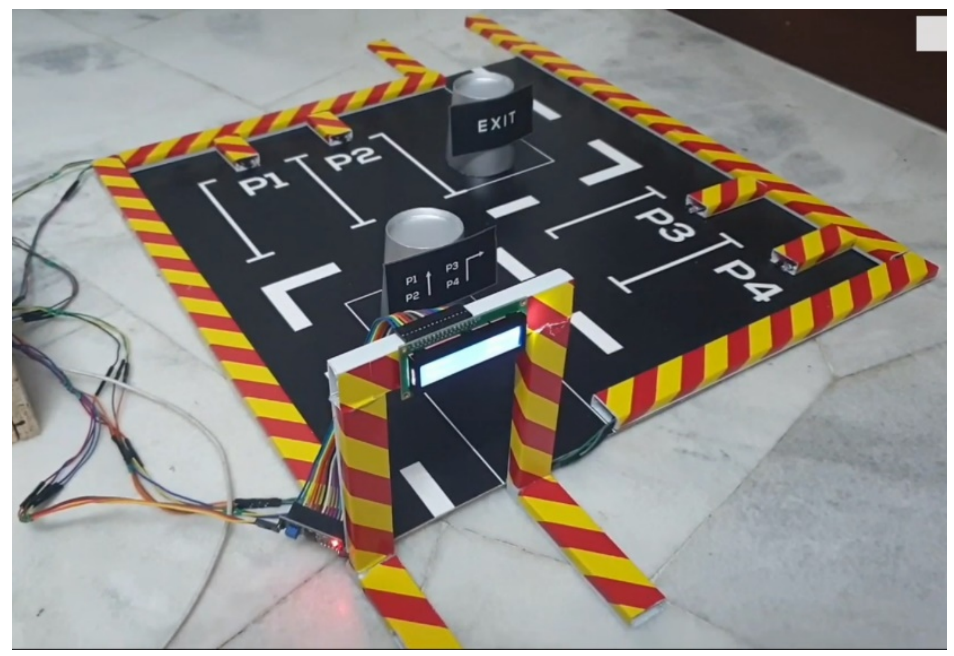

Figure 2: Prototype of loT based Car Parking Management System using IR Sensor

Meanwhile, the interface of the car parking management system was created using PHP language. The data was received from IR sensor through microcontroller and stored in the database. Figure 3 shows the availability of the parking slot displayed by the system.

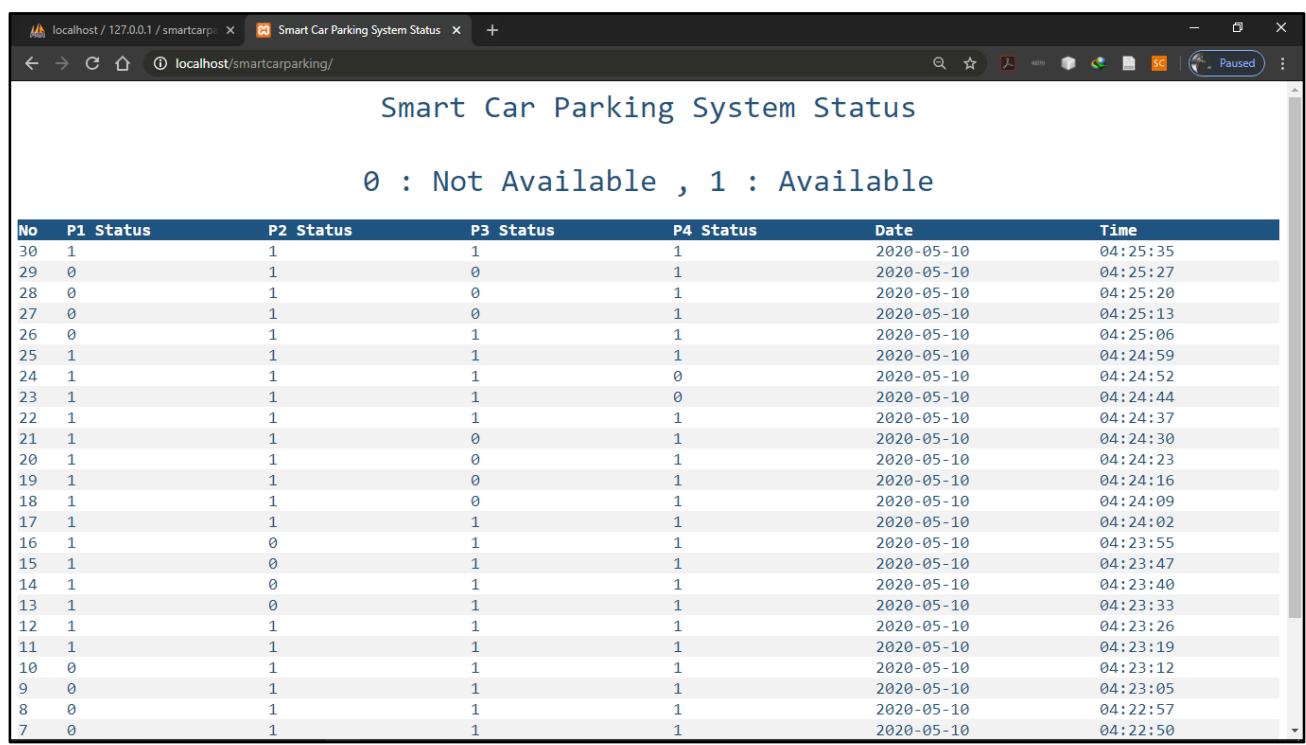

Figure 3: Car Parking Management System Interface 


\section{Simulation and Experiment Details}

Based on the prototype for the proposed parking system and its experimental hardware and software setup in Figure 2, there are 4 IR sensors located in front of the parking slot for detecting the presence and absence of the cars. Whenever a car enters the parking slot, a LCD display board is present at the entrance which clearly gives information about the exact location of the available parking slot.

In every parking slot, an IR sensor is present to detect the absence or presence of the car, and these sensors are connected to the NodeMCU microcontroller. Then, the microcontroller sending the IR sensor data to the database whenever a car enters or leaves the parking slot and the data is continuously updated to the database in the server. In this proposed parking system, the sensors are used as input devices and LCD screen is used as output device. When a car enters or leaves the parking slot, the LCD screen will be updated respectively. Figure 3 shows the LCD screen status when the parking slots are available indicated by symbol '//' and not available indicated by symbol 'XX'.

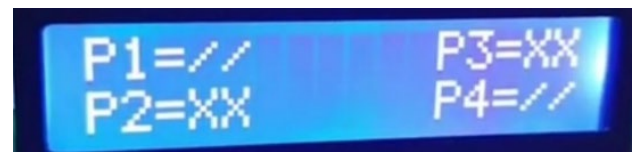

Figure 3: LCD Screen Status

The IR sensors detect the car and send the data to the database through the WiFi connection. Figure 4 illustrated the parking status of car parking management system. This page is continuously update on the IR sensor value about the availability of the parking slot. The 0 value shows that the parking is not available, while the 1 value means the parking slot is available. Besides, the date and time of the car enter and leave the parking slot also recorded in the database.

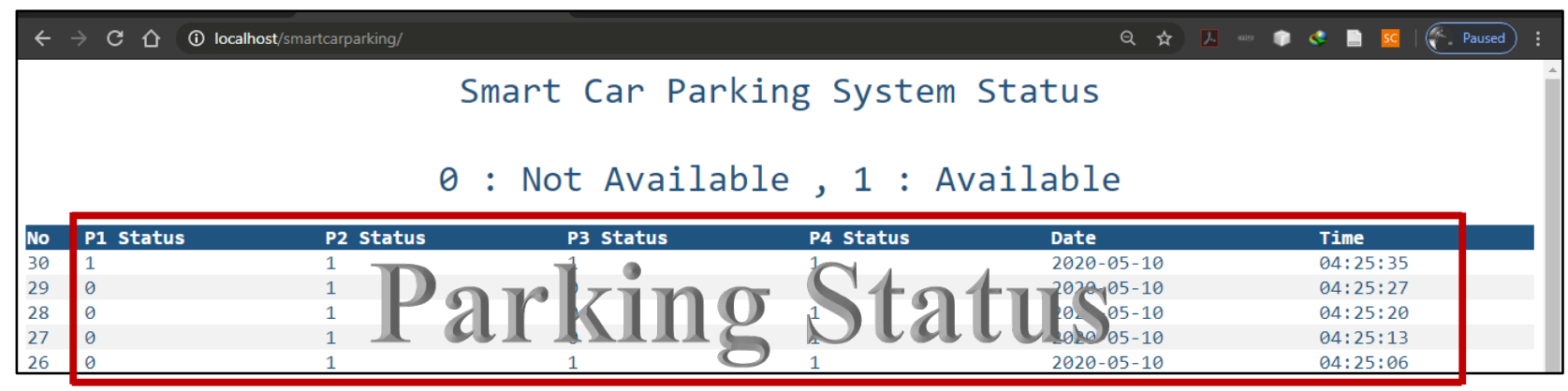

Figure 4: Parking Status for the Car Parking Management System

The functionality of the prototype for the proposed parking system was tested to ensure that there is no problem with the system. Therefore, the system must free from any error that may occur in the language error, logic error and hardware configuration failure. In order to perform the test for the prototype, several cases were discussed.

Case 1: Whenever the parking slot is empty, the LCD screen status displays the availability of the car parking slot indicated using '//' symbol. Figure 5 represents that all the four spaces are available, and the car can park in those parking slots.

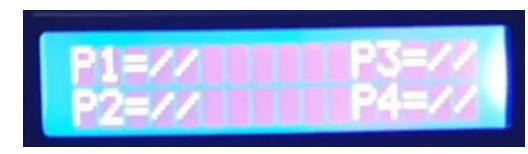

Figure 5: LCD screen status (four spaces are available) 
Case 2: When the first car enters to the parking slot 1 (P1), the LCD screen displays the updated status of the availability of the car parking slot $\mathrm{P} 1$ to the ' $\mathrm{XX}$ ' symbol indicates the parking slot is not available as shown in Figure 6. The next car will go to either P2, P3 or P4 parking slot.

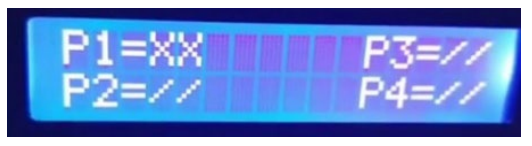

Figure 6: LCD screen status ( $P 1$ is not available)

Case 3: When the first car leaves the parking slot 1 (P1), the LCD screen displays the updated status of the availability of the car parking slot P1 to the ' $\mid \backslash$ ' symbol indicates the parking slot is available as shown in Figure 7.

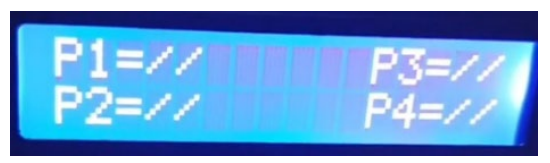

Figure 7: LCD screen status (updated status for the availability of P1 parking slot)

Case 4: When the second car enters to the parking slot 2 (P2) and third car enters to the parking slot 3(P3) the LCD screen displays the updated status of the availability of the car parking slot P2 and P3 to the 'XX' symbol indicate the parking slot is not available as shown in Figure 8. The next car will go to either P1 or P4 parking slot until all parking slots are filled by the cars.

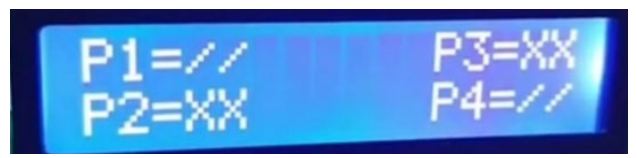

Figure 8: LCD screen status (P2 and P3 are not available)

\section{The User Acceptance Test}

The proposed prototype was evaluated to determine the performance and to ensure all requirements accomplished. The User Acceptance Test (UAT) was conducted by using a set of questionnaires to the respective respondents. This testing was performed to make sure it can handle the required task according to specifications and to determine whether the system satisfies the acceptance criteria from the users. The respondents were randomly selected from drivers who had experience in any car parking system previously. A quantitative research approach was used for data collection by analyze a survey questionnaire collected from respondents using arithmetic mean technique.

To evaluate the user acceptance test for the proposed car parking system, the study was tested to thirty (30) respondents. The experiment was conducted by given a demonstration on how the system works to the respondents. Then, they were required to answer a set of questionnaires, which consist of twelve (12) questions and divided into four components, which included Perceived Ease of Use (PEU), Perceived Usefulness (PU), Attitude (ATT) and Intention to Use (BI). The data were analyzed using arithmetic mean technique based on the ranking score value. The participants required to rate the answer with the scale of 1 to 5, which was strongly disagree, disagree, neutral, agree and strongly agree.

Then, overall mean was calculated and classified into three categories, which is negative, neutral and positive based on the range of mean value in between zeros to five as shown in Table 1. This table will be used to identify the level of user's acceptance toward the proposed parking system. 
Table 1: Range of Mean Value

\begin{tabular}{|l|l|}
\hline Category & Range of Mean \\
\hline Negative & $0.00-1.66$ \\
\hline Neutral & $1.67-3.33$ \\
\hline Positive & $3.34-5.00$ \\
\hline
\end{tabular}

Figure 9 summarizes the results for the identified criteria and total mean for each component respectively. The results showed that the targeted respondents were satisfied and positively accepted all functionalities and features provided by the proposed car parking system. This can be indicated by the total mean result for the Perceived Ease of Use (PEU) received 4.40 and Perceived Usefulness (PU) received 4.30 respectively. On the other side, most of the participants wanted to use the proposed car parking system because the system is able to display the exact location of an available vacant parking space to the driver and can save their time when they want to find a parking, based on the total mean results obtained 4.40 for Attitude (ATT) and 4.40 for Intention to Use (BI). Besides, the overall total mean for the UAT was 4.34, which means positive feedback from the participants.

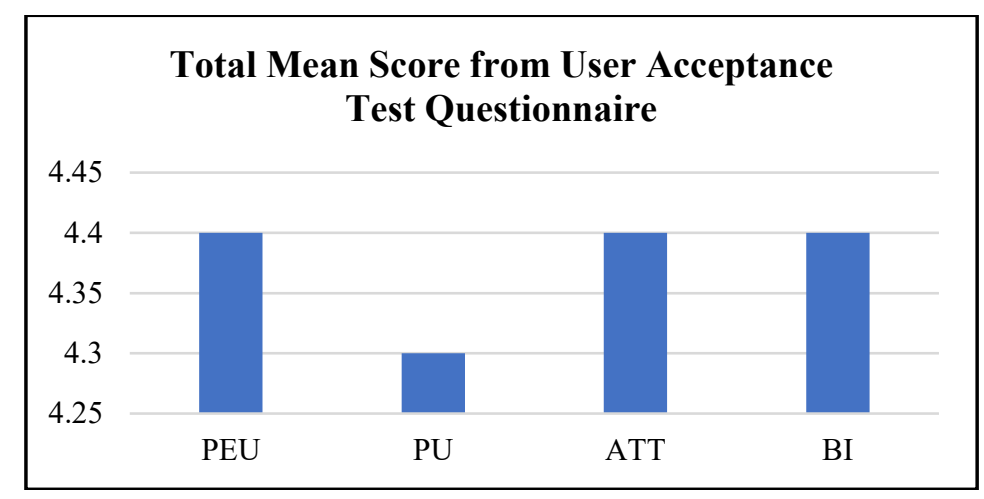

Figure 9: Total Mean Score for Each Component for UAT

\section{RESULTS AND DISCUSSION}

IoT based Car Parking Management System using IR sensor was able to perform its function such as detect the presence or absence of a car, display the availability status of parking slot and store the data of IR sensor into the database. Moreover, the advantage of the proposed parking system, it be able to show the exact location of parking slot to the user. Based on the results obtained, it was proven that the proposed car parking system using IR sensor was a good idea and a great system to develop, and it indicates that the respondents were positively accepted the proposed parking system in order to minimize and reduce the problem for parking of vehicles, especially the time being wasted in searching for the available parking spaces.

\section{CONCLUSION AND FUTURE WORK}

This paper presents an efficient solution for finding a parking space and Internet of Things (IoT) was the main concept used to develop the proposed parking system using IR sensor. The IoT based Car Parking Management System using IR sensor was a prototype that was developed to assist the drivers in finding a vacant or available parking slot. This proposed parking system used IR sensor to detect the presence and absence of a car in order to know the availability status of parking slot. The parking slots are continuously 
monitored, and the data is continuously updated in the LCD screen. The LCD screen displays the exact location of the availability status of parking slot. Meanwhile, the data from IR sensor also stored in the database. The prototype of the proposed parking system was developed for single storage parking slot, but this model can be extended for multi storage parking. Besides, the car parking management system interface was provided to record the status of a parking slot and the exact time a car enters or exits a parking slot for the administrative management. The outcome from this proposed parking system is useful to be implemented at any parking zone areas to help driver finding a vacant parking easily. Moreover, the proposed parking system was also measured using a user acceptance test to see the acceptance of people towards the proposed parking system. Most of the respondents positively accepted the proposed parking system using IR sensor and found that it was a great idea to develop a parking system that can assist drivers in finding a vacant parking slot easily. Hence, it gives convenience to the users as it can save their time, energy and fuel consumption. This work can be further extended by developing an application that allows the user to navigate, locate and reserve a parking slot in online using mobile app.

\section{REFERENCES}

Agarwal, P., Sharma, S., Gupta, L., \& Manideep, B. (2017). Smart Electronic Garbage Management System- Based IOT. International Journal of Soft Computing and Engineering (IJSCE), 7(1), 9396.

Ali, Z. H., Ali, H. A., \& Badawy, M. M. (2015). Internet of Things (IoT): Definitions, Challenges and Recent Research Directions. International Journal of Computer Applications, 128(1), 37-47.

Chowdary, U. V., Rohith, K., Sandeep, P., \& Ramu, M. (2015). Home Automation System Using IR Sensors. International Journal of Electrical and Electronic Engineering (IJEEE), 4(6), 11-16.

Deekshitha, Disha, D., Malavika, \& Soumya. (2017). Traffic Monitoring System Using IR Sensors. International Journal of Advance Research, Ideas and Innovations in Technology, 3(3), 10451057.

Kousalya, S., Priya, G. R., Vasanthi, R., \& Venkatesh, B. (2018). IOT Based Smart Security and Smart Home Automation. International Journal of Engineering Research \& Technology (IJERT), 7(04), 43-46.

Larisis, N., Perlepes, L., Stamoulis, G., \& Kikiras, P. (2013). Intelligent Parking Management System Based on Wireless Sensor Network Technology. Sensors and Transducers Journal, 18(Special Issues), 100-112.

Mitra, S., Mishra, P., Daniel, J. A., \& Balaji, S. (2019). Smart Light for Home with Automatic Direction and Intensity Adjustment using Arduino. International Journal of Recent Technology and Engineering (IJRTE), 8(1S4), 479-484.

Morajkar, P., Bhor, V., Pandya, D., Deshpande, A., \& Gurav, M. (2015). Smart Garbage Management System. International Journal of Engineering Research \& Technology (IJERT), 4(03), 11171120.

Rani, L. P. J., Kumar, M. K., Naresh, K. S., \& Vignesh, S. (2017). Dynamic Traffic Management System using Infrared (IR) and Internet of Things (IoT). Third International Conference on Science Technology Engineering Management (ICONSTEM) 2017, 353-357. 
Rao, Y. R. (2017). Automatic Smart Parking System using Internet of Things (IOT). International Journal of Engineering Technology Science and Research, 4(5), 225-228.

Srikanth, S. V., Pramod, P. J., Dileep, K. P., Tapas, S., Patil, M. U., \& Sarat, C. B. N. (2009). Design and Implementation of a Prototype Smart PARKing (SPARK) System Using Wireless Sensor Networks. International Conference on Advanced Information Networking and Applications Workshops 2009, 401-406.

V. Reve, S., \& Choudhri, S. (2012). Management of Car Parking System Using Wireless Sensor Network. International Journal of Emerging Technology and Advanced Engineering, 2(7), 262-268. 